\title{
THE LATERAL DISTRIBUTION OF EVENT-RELATED POTENTIALS DURING SENTENCE PROCESSING
}

\author{
Marta Kutas and Steven A. Hillyard \\ Department of Neurosciences, University of California, San Diego La Jolla, CA 92093. U.S.A.
}

(Received 20 April 1982)

\begin{abstract}
Event-related brain potentials (ERPS) were recorded from adults as they cead 160 different sentences, half of which ended with a semantically anomalous word. These deviant words elicited a broad, negative component ( $\mathrm{N} 400$ ). Measured in the difference wave between ERPs to incongruous and congruous endings, the $\mathrm{N} 400$ was slightly larger and more prolonged over the right than the left hemispherc and diminished in amplitude over the course of the experiment. A left-greater-than-right asymmetry was again observed in the slow. positive ERP elicited by the first six words in the sentences, being most pronounced for subjects having no left-handers in their immediate family.
\end{abstract}

DESPITE an intensive search over the past decade for lateralized electrophysiological signs of linguistic processing in the brain, findings to date from investigations of event-related potentials (ERPs) do not form a coherent picture. A number of studies have reported an amplitude asymmetry in the ERPS recorded over the language areas and their right hemisphere homologues during tasks requiring linguistic or semantic analyses [1-7]. Others have observed that ERP activity over the left hemisphere is more sensitive to the linguistic properties of the eliciting stimuli than is right hemispheric activity [8-11]. However, a sizeable number of reports have noted an absence of hemispheric asymmetry in the ERPS obtained during the performance of language-related tasks [12-18].

Several reviewers of this literature have suggested that the paucity of reliable ERP asymmetries may be due at least in part to incomplete engagement of the language system by the tasks employed $[14,19,20]$. For example, the repeated presentation of isolated syllables, words, or a limited number of sentences may not tax language mechanisms as fully as would normal conversation or reading. Recently, we have reported a series of experiments involving recordings of ERPs from subjects as they read meaningful seven-word sentences, presented one word at a time [21-23]. Unexpected, semantically anomalous words placed at the ends of some sentences elicited a large negative wave (N400) having a parieto-central scalp distribution. We suggested that this $\mathrm{N} 400$ might be a marker of semantic evaluation processes following the interruption of the sentence analysis by the inappropriate word. While this particular interpretation may or may not be correct, the dependence of the N400 on linguistic analyses which are generally presumed to have lateralized cortical substrates led us to investigate whether this ERP would show lateral asymmetries at the scalp.

In our initial reading experiments $[21,22]$, the $N 400$ was found to be virtually absent from lateral frontal scalp areas (F7 and F8). In a third experiment [23], recordings were made with a short time-constant from temporo-parietal leads, roughly over Wernicke's area and its right hemisphere homologue; both the $\mathrm{N} 400$ elicited by semantically incongruous words and the "difference N400" (incongruous minus congruous ERP) were slightly larger and more 
prolonged over the right than the left side. That experiment also confirmed our earlier finding of a left-greater-than-right amplitude asymmetry in a slow positivity associated with the first six words in the sentences. This latter asymmetry was influenced by familial handedness, being attenuated for right-handed subjects who had left-handers in their immediate family. The present study was designed to evaluate the reliability of these laterally asymmetric ERPS during reading and to map their distributions more thoroughly.

A second aim of this study was to determine whether the $N 400$ would be maintained when a substantial fraction $(50 \%)$ of the sentences ended anomalously. In previous studies. the probability of a semantically incongruous ending was set at 0.25 because we had surmised that a higher frequency of deviant events might attenuate the associated endogenous components, as seems to occur with other late ERPs such as the P300 [24]. It was, therefore. of interest to see if $\mathrm{N} 400$ would be elicited at higher frequencies of semantic deviation, not only to contrast this effect with other expectancy-sensitive ERPS, but also to test the utility of $\mathrm{N} 400$ as a repeatable probe of semantic processing in a quasi-natural language context. Finally, increasing the proportion of anomalous sentences allowed a more precise examination of long-term changes in $\mathrm{N} 400$ amplitude across the test period.

\section{METHODS}

\section{Subjects}

Fourteen young adults (six female, age range 18-24 yr) were paid for participating in the experiment. Twelve of the subjects were right-handed according to self-report and the Edinburgh Inventory [25], and three of these had left-handed relatives in their immediate family. Of the remaining subjects, one was left-handed and the other ambidexterous; both had sinistral relatives.

Stimuli

Words were displayed in the form of brightened dot matrices on a CRT controlled by an Apple II microcomputer.

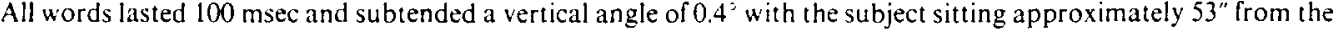
screen.

\section{Recording system}

EEG activity was recorded from seven scalp electrodes. each referred to linked mastoids. Five were placed according to the International 10-20 convention [26] at $\mathrm{Cz}$ and at left and right central (C3, C4), and temporal (T3. T4) locations. Symmetrical temporo-parietal electrodes were placed lateral (by $30 \%$ of the interaural distance) and $12.5 \%$ posterior to the vertex. These placements were situated approximately over Wernicke's area and its right hemisphere homologue. Eye movements and blinks were monitored via an electrode placed on the lower orbital ridge referred to linked mastoids. A right vs left external canthal montage was used to record lateral eye movements

The Cz, C3 and C4 leads and the lateral eye recordings were amplified with Grass 7P1 preamplifiers (system bandpass DC to $40 \mathrm{~Hz}$, half-amplitude cutoff). The other lateral scalp placements were amplified with Grass 7P1 preamplifiers having $8 \mathrm{sec}$ time constants. Lower eye activity was amplified with a Grass 7P5 preamplifier (system bandpass down $3 \mathrm{~dB}$ at 0.15 and $150 \mathrm{~Hz}$ )

The EEG, EOG and stimulus trigger codes were recorded on FM tape, and analog to digital conversion was performed off-line by a PDP $11 / 45$ computer. A $1024 \mathrm{msec}$ epoch of EEG data beginning $100 \mathrm{msec}$ before the onset of each stimulus was analyzed at a sampling rate of $4 \mathrm{msec}$ per point.

\section{Procedure}

Subjects were tested in one session that lasted $21-3 \mathrm{hr}$, while reclining in a comfortable chair. They were informed that they would be presented with a series of simple, English sentences, one word at a time, and that each sentence would form a grammatically correct, meaningful unit. They also were told that the sentences were similar to one another in grammatical structure and that some might seem very familiar. Their instructions were to read each of the sentences silently in order to answer questions about their contents at the end of the experiment.

The start of each sentence was signalled by a warning stimulus consisting of XXXXX. This was followed 1 sec later by the sequential presentation of seven words at intervals of $1 \mathrm{sec}$, the last of which was followed by a period to indicate sentence completion. After a $2 \mathrm{sec}$ delay the next sentence was presented, and so on. 
At the beginning of the session. subjects were exposed to 10 practice sentences with no ER Ps recorded. Two of these were completed by a semantically anomalous word. The practice trials were followed by eight experimental series of 20 sentences each. Each sentence was unrelated to the others. Of these 160 sentences. half were completed by semantically appropriate (congruous) words and half by inappropriate words (e.g. "There are too many people in wallet." and "He listed his occupation as a chocolate.") These two types of sentences were presented in random order. Each series of 20 sentences was followed by a $2-3 \mathrm{~min}$ rest period.

Following the ERP recordings, subjects were given a memory recognition questionnaire on the sentences. The first test listed the first six words of 42 different sentences. 31 of which were selected from the sentences just seen and Il of which had not been shown. The subject's task was to check whether each sentence was "old" or "new" and to fill in the word they remembered as completing each of the "old" sentences. The subjects were then shown a list of all $I 60$ of the completed sentences and were asked to rate each of the last words as to their unexpectedness on a seven-point scale.

\section{RESULTS}

\section{General characteristics of ERPs}

Figure 1 shows the superimposed ERPs from individual subjects to the four different classes of stimuli. The corresponding grand average waveforms over all subjects are shown below. The ERPs to all stimuli were characterized by a negative peak at $120-150 \mathrm{msec}$ (N136) and a positive peak at $180-250 \mathrm{msec}$ (P220). The responses to the warning stimulus (WS) included a small and highly variable positivity at around $400 \mathrm{msec}$ ( $\mathrm{P} 400)$.

WS

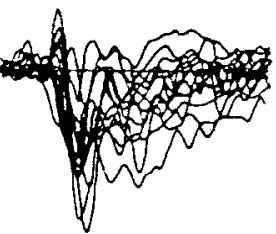

N136

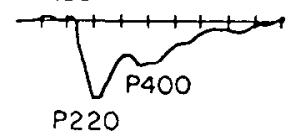

0300600
Words $1-6$
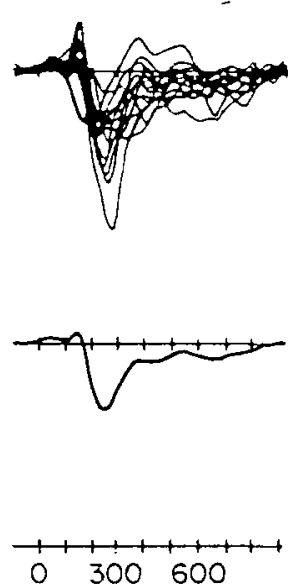

Word 7

(Congruous)
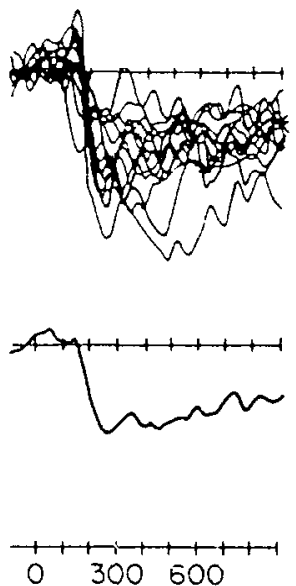

Word 7

(Incongrous)
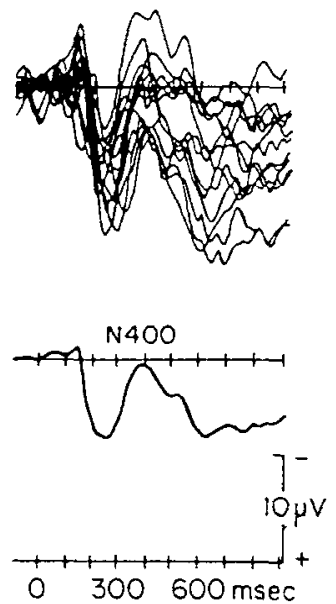

FIG. 1. ERPs to the warning stimulus (WS), to words $1-6$ (averaged together), and to the congruous and incongruous seventh words. Each of the superimposed tracings in the top row is the averaged ERP from a different subject. The ERPs in the bottom row are the corresponding "grand average" waveforms over all subjects $(N=14)$, recorded at the vertex.

The ERPs to the final words in the sentences were also marked by appreciable inter-subject variability, but in each case the semantically congruent ERPS were associated with a sustained late positivity in the $300-900 \mathrm{msec}$ range. The ERPs to the incongruous words, on the other hand, included an additional negative-going wave between 300 and $600 \mathrm{msec}$ (N400). Thus, the ERPs elicited by the congruent and incongruent seventh words differed significantly in the $300-600 \mathrm{msec} z o n e[F(1,13)=73.19, P<0.001$, for area measure relative 
to 90 msec pre-stimulus baseline]. This difference was maximal around $380 \mathrm{msec}$ at the vertex and averaged $-8.63 \pm 0.65 \mu \mathrm{V}$ relative to the baseline. The congruous and incongruous seventh word ERPs did not differ significantly from one another in the $600-900 \mathrm{msec}$ region.

\section{Comparison of ERPs over left and right hemisphere's}

Warning stimulus and words $1-6$. The ERPs from the lateral electrodes averaged across all 14 subjects are depicted in the first two columns of Fig. 2. The ERPs elicited by the WS were

WS

(all Ss)

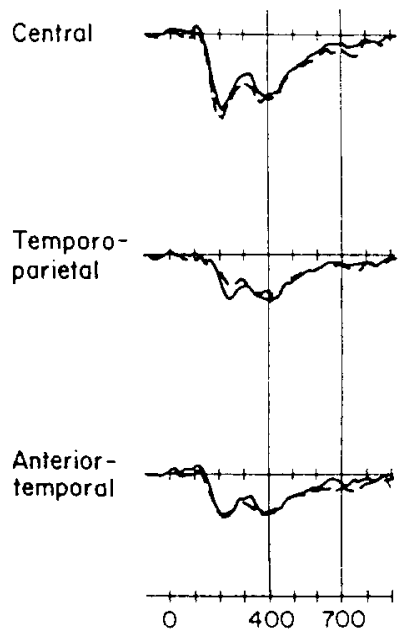

Words $1-6$

(all Ss)

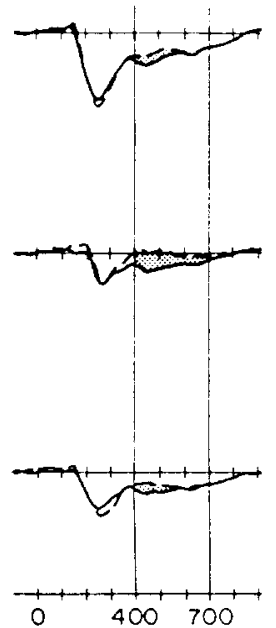

Words $1-6$ (w/o L.H. Rels.)

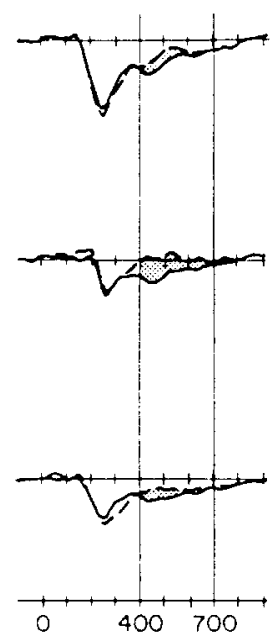

Words $1-6$ (w) L.H. Rels.)

\footnotetext{
- left hemisphere
}

right hemisphere

FIG. 2. Superimposed ERPs over the right and left hemispheres from three pairs of homologous locations. Comparisons are shown for ERPs elicited by the warning stimulus (WS) and by words one-six (averaged together). The ERPS in the first two columns are averages across all 14 subjects. The ERPs in the last two columns are segregated according to whether the subjects did $(N=9)$ or did not $(N=5)$ have any left-handed relatives in their immediate family.

nearly symmetrical, whereas the ERPs averaged over the first six words in the sentences showed a prolonged positivity that was larger over the left than the right hemisphere, particularly over the temporo-parietal sites.

This left-right hemispheric difference, quantified as the area of the region $400-700 \mathrm{msec}$ post-stimulus relative to a $90 \mathrm{msec}$ pre-stimulus baseline (shaded region between vertical lines), was evident in each of the electrode pairs, but specific comparisons indicated that this lateral asymmetry was significant only at the temporo-parietal sites $[F(1,13)=6.22$, $P<0.03]$. Inspection of the individual subjects' waveforms revealed that the left-greaterthan-right positivity to words $1-6$ was larger in the right handers without left-handed relatives. While this difference between the groups was present at all of the electrode pairs, planned comparisons showed that significant asymmetry was restricted to the temporoparietal locations $[F(1,8)=7.24, P<0.02]$. There were no significant sex differences in ERP laterality. 
Seventh words. In contrast to the ERPs elicited by words $1-6$, the late positive shift in the ERPs to the congruent seventh words was approximately $1 \mu \mathrm{V}$ larger over the right than the left hemisphere for each of the lateral electrode pairs $(P<0.01$ for each pair for the area measure between 300 and $900 \mathrm{msec}$ ) (see Fig. 3). The degree of asymmetry was not influenced

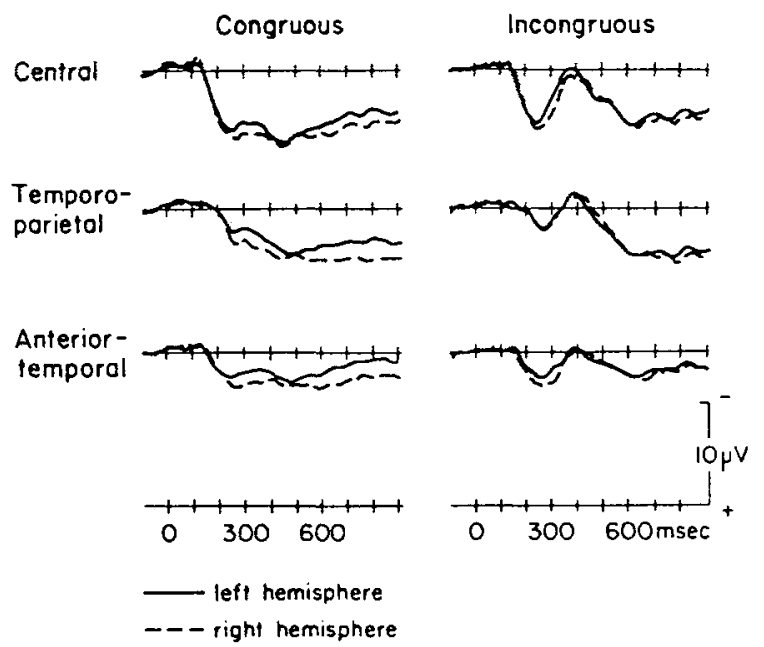

FIC. 3. The grand average ERPs (across all 14 subjects) elicited by the semantically congruous and the semantically incongruous seventh words. In each case, the ER Ps recorded from homologous sites over the two hernispheres are superimposed.

by subjects' familial handedness. The ERPs elicited by the incongruent seventh words also showed a slight tendency for a right-more-positive-than-left asymmetry in the $200.400 \mathrm{msec}$ and $600-900 \mathrm{msec}$ ranges, while the $\mathrm{N} 400$ itself (at $400-500 \mathrm{msec}$ ) appeared slightly more prolonged over the right hemisphere. However, none of these asymmetries were significant.

Difference waves. The lateral distribution of the $\mathrm{N} 400$ difference waves obtained after a point by point subtraction of the congruent from the incongruent seventh word ERPs is shown in Fig. 4. Although the $\mathrm{N} 400$ difference wave averaged over all subjects was approximately $1 \mu \mathrm{V}$ larger over the right than the left hemisphere at each pair of lateral electrode sites, neither a base-to-peak nor an area measure of the negativity revealed a significant lateral asymmetry. The $\mathrm{N} 400$ was approximately $1 \mu \mathrm{V}$ larger at the central than at the temporo-parietal sites, which in turn were some $2 \mu \mathrm{V}$ larger than at the anterior temporal sites [anterior-posterior electrode main effect, $F(2,26)=28.79, P<0.001$ ]

A significant electrode location by hemisphere interaction was found for subjects without left-handers in their immediate family [for area 300-600 msec measure, $F(2,16)=3.72$, $P<0.05]$. This was due to a right-greater-than-left negativity that was significant only at the temporo-parietal locations $[F(1,8)=5.90, P<0.04]$.

\section{Seventh word ERPs by quarters}

The ERPs to the congruent and incongruent seventh words and their difference waveforms were averaged separately for each quarter of the experiment (Fig. S). Visual inspection of these data indicates that the ERPs elicited by the semantically incongruent words remained essentially unchanged while the amplitude of the late positivity elicited by the congruent 


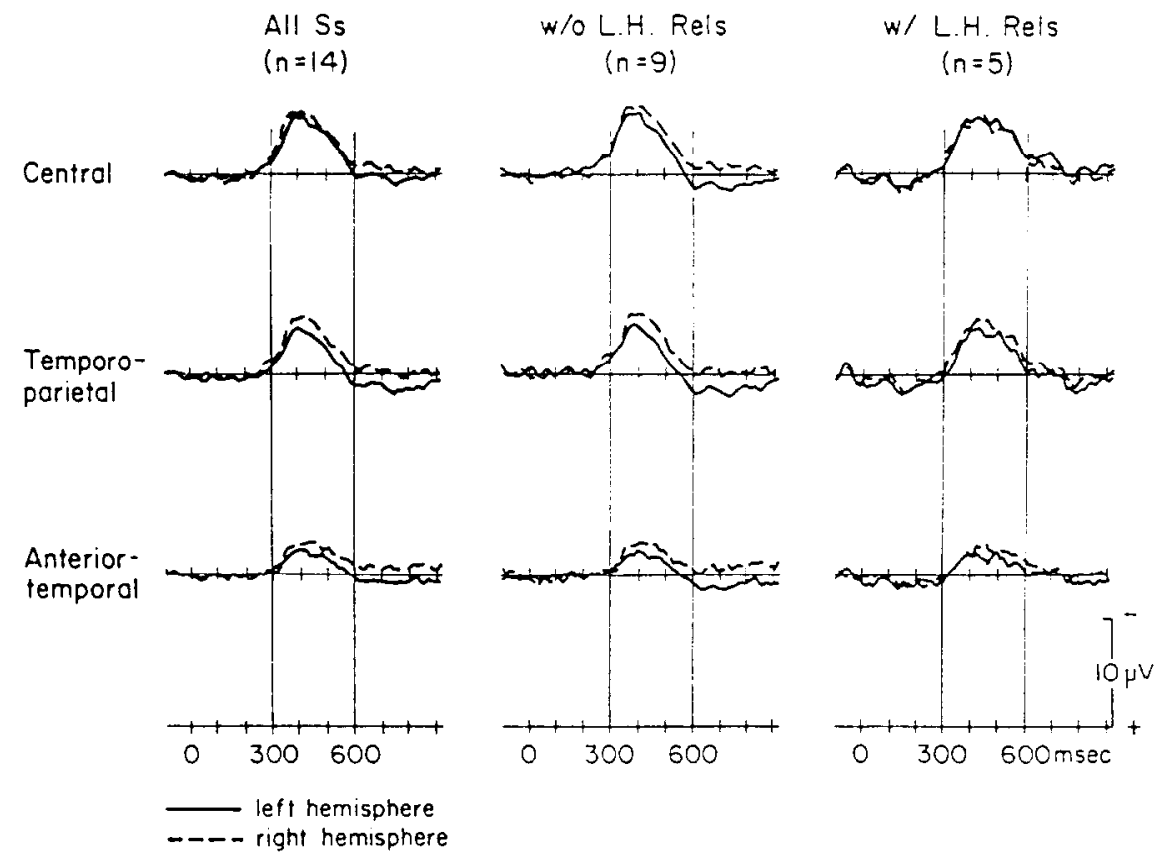

Fig. 4. The difference $\mathbf{N} 400$ waves recorded from lateral electrode pairs averaged across all subjects (left) and broken down into subjects with and without sinistrals in their immediate family.

\section{Word 7 (Incongrous)}

QUARTER

IST

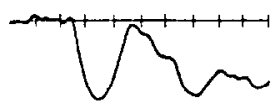

2ND

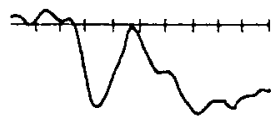

3RD

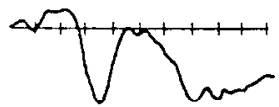

$4 \mathrm{TH}$

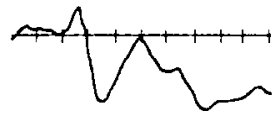

$$
0300600
$$

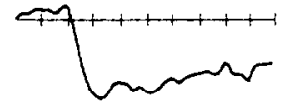

Word 7 (Congruous)
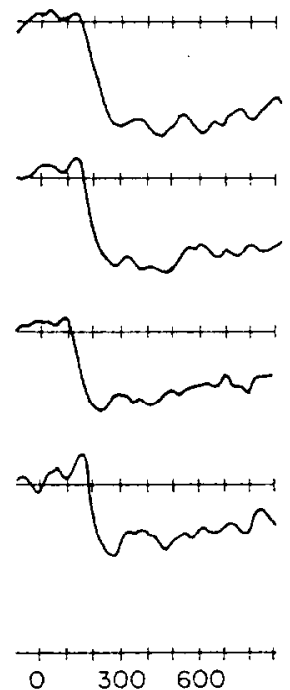

Difference.
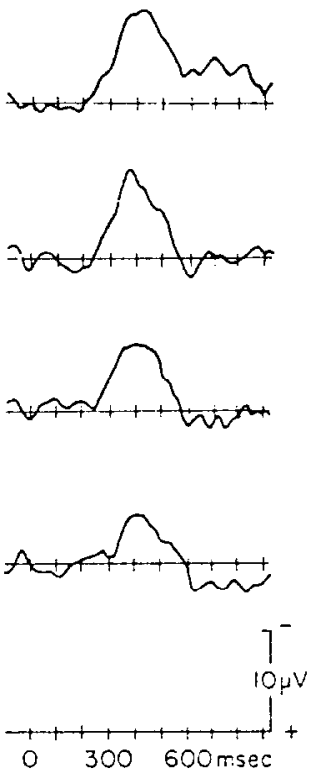

Fig. 5. The grand a verage ERPs $(N=14)$ elicited by semantically congruent and incongruent seventh words, and the difference waveform obtained by subtracting them, shown as a function of the quarter of the experiment in which they were recorded. Each ERP represents an average over 15-20 
words declined systematically. As a result. the amplitudes of the corresponding N400 difference waves also declined over the experiment.

The ERPs to the incongruous final words differed between quarters only in the amplitude of the N136 component, which was significantly larger (by $11.5 \mu \mathrm{V}$ ) during the second than the first half of the experiment [for base-to-peak measure, main effect of quarter was $F(3,39)=3.49 . P<0.03]$. Measures of the $N 400$ remained unchanged across quarters.

The N136 elicited by the congruent final words was also largest towards the end of the recording session $[F(3.39)=3.15, P<0.04]$. In addition, the amplitude of the late positivity in the ERPs to congruent words was reduced significantly in the course of the experiment [for area 300-600 measure, $F(3.39)=5.31 . P<0.003$; for area $600-900$ measure $F(3.39)=6.67$, $P<0.001]$.

The N400 difference waves similarly were reduced in amplitude from the first to the last quarters [for area 300-600 measure, $F(3.39)=3.99 . P<0.02$ ]. In peak amplitude, the N400 difference wave decreased by approximately $2 \mu \mathrm{V}$ from the first to the second quarters, and by $0.5-1.0 \mu \mathrm{V}$ thereafter. The amplitude of the late negativity in the region $600-900 \mathrm{msec}$ post-stimulus also declined during the experiment $[F(3,39)=5.75, P<0.002]$.

\section{Behavioral data}

Semantic incongruity ratings. Behavioral assessments of the subjects reactions to the last words were derived from their responses on a seven-point rating scale, where 1 indicated that the word was "expected" and 7 that it was "totally unexpected". The mean ratings for congruous $(1.61 \pm 0.13)$ and incongruous words $(6.28 \pm 0.17)$ diverged sharply (Mann-Whitney $U, P<0.001$ ). These ratings did not differ over quarters for the congruous $(1.58,1.61,1.63,1.71)$ or for the incongruous $(6.27,6.18,6.39,6.31)$ words.

Memory/recognition questionnaire. The subjects correctly identified an average of $65 \%$ of the "old" six word sentences and misclassified an average of $24 \%$ of the "new" sentences on the list as belonging to the set they had just seen. They correctly filled in the seventh word that was actually shown for $84 \%$, of the sentences that had ended appropriately. However, while they recognized $39 \%$ of the sentences that had ended inappropriately, they were able to fill in the correct word for only $10 \%$ of them.

\section{DISCUSSION}

As in previous reports, words presented in this silent reading task elicited long latency ERPS that differed as a function of word position and meaningfulness [16, 21-23, 27]. Each of the initial six words in these sentences was associated with a small positive ERP sustained over $300-900$ msec post-stimulus, while the final words were followed by considerably larger positive baseline shifts. In addition, when the last word was semantically inappropriate to the context of that sentence a negative component (N400), of maximal amplitude over centralparietal scalp regions, was superimposed upon the positive-going shift.

As reported previously [22-23], the late positivity elicited by words $1-6$ in the sentences was larger over the left than the right temporo-parietal scalp. The size of this asymmetry was again found to be relatively smaller for subjects having left-handers in their immediate families. While this small, highly consistent ERP asymmetry may be a sign of lateralized linguistic processing, this remains speculative in the absence of appropriate control evidence from non-language tasks. Nonetheless, since the asymmetry was not present in the ERPs to the warning stimuli and has not been observed in studies employing repetitive sentences [16], it is reasonable to suggest that these slow shifts may be associated with the active assimilation 
of natural language. Furthermore, the reduction of this ERP asymmetry in subjects with lefthanded relatives parallels the observations of smaller laterality effects in such persons on a variety of behavioral measures that have been taken to reflect hemispheric specialization for language $[28,29]$.

These data are in line with several recent reports of a prolonged positive electrogenesis in the later regions (post $300 \mathrm{msec}$ ) of the ERP. larger over the left than the right hemisphere for language-related tasks [7] and larger over the right than the left in tasks requiring tactile discrimination [30] or spatial analysis [31]. While these asymmetries appear to have an opposite laterality for language and non-language tasks, our present understanding of scalp ERPs does not permit a definite interpretation of such asymmetries in terms of specific hemispheric functions.

A significant lateral asymmetry was also observed in the $N 400$ difference waves (incongruous minus congruous endings). This hemispheric difference was quite small, but it has also been observed consistently in two prior studies [23, 32]. Figure 6 shows the rightgreater-than-left asymmetry in the $\mathrm{N} 400$ and in the difference waves in a previous study by KI'TAS [32] which differed from the present one in two minor ways: (a) the words were presented at a rate of 2 per sec, and (b) the probability of a sentence ending with a semantically anomalous word was set at 0.25 . Again, the $\mathrm{N} 400$ was larger and more prolonged over the right side of the head. (The area of the difference wave between 500 and $700 \mathrm{msec}$ averaged $28 \pm 194 \mu \mathrm{V} \mathrm{msec}$ at the left temporo-parietal site and $-458 \pm 101 \mu \mathrm{V}$ msec at the right temporo-parietal site $[F(1,6)=9.59, P<0.02]$ ). While this asymmetry may derive in part from overlap with other late components, it appears that the negativity associated with semantic anomaly has a right hemispheric preponderance.

It should be noted that the asymmetry of the N400 difference wave is a function of asymmetries in the ERPs to both the incongruous and congruous final words. While the

Incongruous
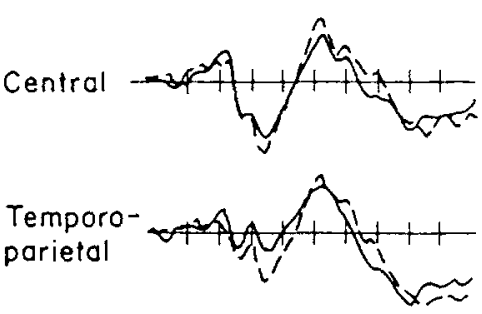

Anteriortemporal

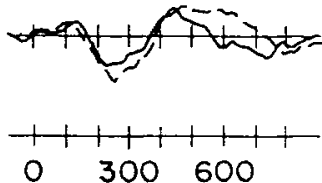

$\mathrm{O}$
Difference Wave
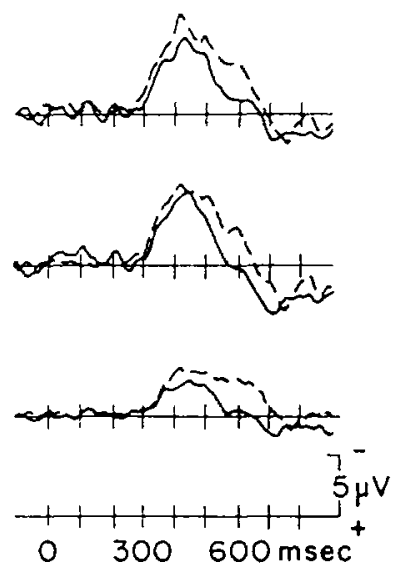

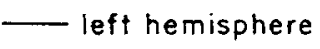

- - right hemisphere

FIG. 6. The grand average ERPs (over all seven subjects in this experiment) elicited by semantically incongruous seventh words (left) and the incongruous minus congruous difference waves (right). In each case, the ERPS recorded from homologous sites over the two hemispheres are superimposed. These data are from KuTAS [32]. 
difference $\mathrm{N} 400$ has consistently been larger over the right hemisphere in all experiments. the ERP to the congruent endings has shown different directions of asymmetry in different experiments $[22,23]$. Whether this variation represents different processing strategies or individual differences between subjects remains to be determined. Interpretation of these asymmetries is doubly difficult because of the likelihood that several overlapping (and possibly interacting) components are produced at the end of the sentences.

If the greater right-sided negativity seen in the $\mathrm{N} 400$ difference wave reflects a preferential processing of semantic incongruity in the right hemisphere, such an effect would appear to be at odds with the generally accepted specialization of the left hemisphere for most aspects of language processing. However, several lines of recent evidence point to an important role for the right hemisphere in the comprehension of high-level semantic, conceptual, and contextual relationships [33-35]. For example. WAPNER et al. [35] found that patients who had sustained brain damage restricted to the right cerebral hemisphere showed no deficiencies in their phonology, syntax or word memory, but did experience difficulty in appreciating the overall contextual framework of narrational and humorous material. WAPNER et al. suggested that right-lesioned patients are impaired at using the normal "plausibility metric". whereby words and statements are judged as being appropriate to a particular context. Since the present experiments also involve judgements about the plausibility of words in sentence contexts, it is conceivable that a right hemispheric specialization for this type of activity may be manifest in a lateralized $N 400$ component. This interpretation of the cognitive functions of the right hemisphere is consistent with findings that patients with right-sided cortical damage are impaired at understanding humor [36], at interpreting metaphors and figures of speech [37], and in appreciating affectively toned situations $[38,39]$-all of which share features in common with the type of semantic anomalies that elicit the $\mathrm{N} 400$.

The N400 amplitudes were substantial in this experiment, even though half of the sentences were completed by semantically anomalous words. In fact, the mean N400 difference wave was equal in amplitude to those observed in two previous experiments in which the probability of an incongruous ending was $0.25[20,22]$. This suggests that the $N 400$ may be less sensitive to changes in the probability of occurrence of the eliciting events than are other late components such as the N200, P300 and slow wave, the amplitudes of which are inversely related to stimulus probability over the range $0.25-0.50$ [39]. However, it should be noted that subjective expectancy seems to be a more potent factor than simple event frequency in determining the amplitude of the $\mathrm{P} 300$ complex. As yet, no metric exists for comparing the expectancies formed during natural language processing with those formed during a random sequence of tones. It may be that highly salient events like semantic anomalies have the same psychological impact over a wide range of probabilities. Furthermore, since linguistic messages are highly constrained and redundant, the persistence of the N400 at higher probabilities of anomaly may reflect the automatic, overlearned character of semantic analyses during reading. Whatever the explanation, the maintenance of a robust $\mathrm{N} 400$ in the face of frequent semantic anomalies should make this ERP useful in reading studies where semantic analyses are tested repeatedly.

Although the $\mathrm{N} 400$ persisted at the $50 \%$ anomaly rate, its amplitude as measured in the incongruous minus congruous difference wave decreased over trials. The nature of this decrement is difficult to evaluate, since the ERP waveforms to the congruous endings were characterized by a late positive shift that also declined steadily throughout the experiment. This positive shift probably consists, at least in part, of the resolution of the CNV that 
develops throughout each sentence [21]. The inference that the CNV and. hence, its resolution are habituating over the course of the experiment is consistent with the parallel increase that was observed in the amplitude of the $\mathrm{N} 136$ component of the ERPs to the final words. The N136 (also termed N1 or N100) is reportedly larger when superimposed on a reduced CNV $[40,41]$.

The ERPs to the terminal words may also include an additional positive component related to "syntactic closure" [16] or some other aspect of sentence completion. If such a positive wave were elicited as a "latent" component at the end of incongruous sentences and habituated over the experiment, then the reduced amplitude of the N400 difference wave would indicate that the $\mathrm{N} 400$ process itself was habituating. On the other hand, if such a positive-going component was not a constituent of the ERP to the incongruous endings or did not decrement over trials, this would imply that the N400 effect itself was stable. as seen in the actual ERPs to the incongruous words (Fig. 5. left).

Another possible interpretation of this long-term change would be to assume that subjects altered their expectations and processing strategies as they learned that many of the sentences were going to be semantically anomalous. Future studies which independently manipulate the various overlapping EKP components and associated psychological processes may clarify these alternatives.

Acknowledgements-This research was supported by a grant from NSF BNS80 -05525 and the Sloan Foundation B1980-35. M. KUTAS is supported by Research Scientist Development Award USPHS 1K02.1H00322/02. We thank J. C. PhILlips and S. VAN Voorhis for their technical assistance and K. Pribram for his editorial advice.

\section{REFERENCES}

1. Morrell, L. and Salaiy, J. Hemispheric asymmetry of electrocortical responses to speech stimuli. Science 174, 164-166, 1971

2. Matsumiya, Y., Tagliasco, V., Lombroso, C. T. and Goodglass, H. Auditory evoked response: Meaningfulness of stimuli and interhemispheric asymmetry. Science 175, 790-792, 1972.

3. Molfese, D. L., Freeman, R. B. Jr. and Palermo, D. S. The ontogeny of brain lateratization of speech and nonspeech stimuli. Brain Lang. 2, 356-368, 1975.

4. Preston, M. S., Guthrif, J. T., Kirsch, I., Gertman, D. and Chil.ns, B. Vers in normal and disabled adult readers. Psychophysiology 14, 8-14, 1977.

5. ThatChER, R. W. Evoked potentials correlates of hemispheric lateralization during semantic information processing. In Lateralization in the Nerious System, S. HaRnad, R. DOTY, L. GoldsteIN. J. JaYnes and G. Krauthamer (Editors), pp. 429-448. Academic Press, New York, 1977.

6. Shucard, D. W., Shucard. J. L. and Thomas, D. G. Auditory evoked potentials as probes of hemispheric differences in cognitive processing. Science 197, 1295-1298, 1977.

7. Preston, M. S. The use of evoked response procedures in studies of rcading disability. In Ecoked Brain Potentials and Behatior, H. Begletter (Editor), pp. 247-268. Plenum Press, New York, 1979.

8. BuchSBAUM, M. and FEDio, $P$. Hemispheric differences in evoked potentials to verbal and non-verbal stimuli in the left and right visual fields. Physiol. Behat. 5, 207-210, 1970.

9. Brown, W. S., Marsh, J. T. and S.MITH, J. C. Evoked potential waveform differences produced by the perception of different meanings of an ambiguous phrase. Electroenceph. clin. Neurophysiol. 41, 13-123, 1976.

10. WoOd, C. C., Goff, W. R. and DaY, R. S. Auditory evoked potentials during speech perception. Science 173 , $1248-1251,1971$.

11. WOOD, C. C. Auditory and phonetic levels of processing in speech perception: neurophysiological and information-processing analyses. J. exp. Psychol. 104, 3-20. 1975.

12. Shrlburite, S. A. Jr. Visual evoked responses to word and nonsense syllable stimuli. Electroenceph. cin Neurophysiol. 32, 17-25, 1972.

13. Shelburine, S. A. Jr. Visual evoked responses to language stimuli in normal children. Electroenceph. clin. Neurophysiol. 34, 135-143, 1973

14. Galambos, R., Be.ison, P., Smith, T. S., SchulmaN-Galambos, C. and Osier, H. On hemispheric differences in evoked potentials to speech stimuli. Electroenceph. clin. Neurophysiol. 39, 279-283, 1975.

15. SMith, T. S., Nielson, B. and Thistle, A. B. Question of asymmetries in auditory evoked potentials to speech stimuli. J. acoust. Soc. Am. 58, 557, 1975. 
16. Friedmax, D.. Simsox, R., RITTER, W. and Rapix, 1. The late positive component (P300) and information processing in sentences. Electroenceph. clin. Veurophysiol. 38, 255-262, 1975.

17. KutAS, M. and DONCHIN, E. Variations in the latency of $P 300$ as a function of variations in semantic categorization. In New Perspectices in Etent-Related Potential Research, D. Otro (Editor), pp. 198-201, U.S. Government Protection Agency. Washington. DC, 1978.

18. SANquist, T. F.. Rohrbalgh, J. W.. SyNdliko, K. and LiNdSLEY, D. B. Electrocortica! signs of levels of processing: perceptual analysis and recognition memory. Psychophysiology 17, 568-576, 1980

19. Donchin, E., Kutas. M. and MCCARTHY, G. Electrocortical indices of hemispheric utilization. In Lateralizalion in the Nertous System. S. HaRiAad, R. Doty, L. GolostelN. J. JaYNes and G. Krauthatier (Editors), pp. 339--384. Academic Press, New York, 1977.

20. HILlYaRD, S. A. and WoODS, D. L. Electrophysiological analysis of human brain function. In Handbook of Behacioral Neurobiology Vol. II. M. S. Gazzavilia (Editor), pp. 345-378. Plenum Press. New York, 1979.

21. KUTAS, M. and HILLYARD, S. A. Reading senseless sentences: brain potentials reflect semantic incongruity. Science 207, 203-205, 1980.

22. Kutas, M. and HillyarD, S A. Reading between the lines: event-related brain potentials during natural sentence processing. Brain Lang. 11, 354-373, 1980.

23. KUTAS, M. and HiLl YARD, S. A. Event-related brain potentials to semantically inappropriate and surprisingly large words. Biol. Psychol. 11, 99-116, 1980.

24. DUNCAN-JOHNSON, C. C. and DONCHIN, E. On quantifying surprise: The variation in event-related potentials with subjective probability. Psychophysiology 14, 456-467, 1977.

25. Oldfield, R. C. The assessment and analysis of handedness: The Edinburgh Inventory. Neuropsychologia 9 , $97-113,1971$.

26. JASPER, H. H. Report of the committee on methods of clinical examination in electromyography. Electroenceph. clin. Neurophysiol. 10, 370-375, 1958.

27. Goto, H., Adachi, T. Utsunomiya, T. and Chen, I.-C. Late positive component (LPC) and CNV during processing of linguistic information. In Human Eloked Polentials Applications and Problems, D. LEHMAN, and E. Callaway (Editors), pp. 121-134. Plenum Press, New York, 1979.

28. VARNEY, N. R. and BENTON, A. L. Tactile perception of direction in relation to handedness and familial handedness. Neuropsychologia 13, 449-454, 1975.

29. ANDREWS, R. J. Aspects of language lateralization correlated with familial handedness. Neuropsychologia 15 , $769-778,1977$.

30. Deswed, J. E. Active touch exploration of extra-personal space elicits specific electrogenesis in the right cerebral hemisphere of intact right-handed man. Proc. natn. Acad. Sci. U.S.A. 74, 4037-4040, 1977.

31. Neville, H. J. Event-related potentials in neuropsychological studies of language. Brain Lang. 11, 300-318, 1980.

32. KUTAS, M. Semantic processing and ERPs: a case study. In E. Donchiv (Editor). Proceedings of Third Annual Carmel Conference on ERPs. Lawrence Erlbaum Press, Hillsdale, N.J., in press.

33. EISENSON, J. Language and intellectual modifications associated with right cerebral damage. Lang. Speech 5, 49-53, 1962.

34. Caramazza, A., Goroon, J., Zurif, E. B. and Deluca, D. Right-hemisphere damage and verbal problem solving behavior. Brain Lang. 3, 41-46, 1976.

35. WAPNER, W., HambY, S. and GarDnfr, $H$. The role of the right hemisphere in the apprehension of complex linguistic materials. Brain Lang. 14, 15-33, 1981.

36. Gardner, H., Ling, K., Flamm, L. and Silverian, J. Comprehension and appreciation of humor in braindamaged patients. Brain 98, 399-412, 1975.

37. WINNER, E. and GARDNER, H. Comprehension of metaphor in brain-damaged patients. Brain 100, 719-727, 1977.

38. Cicone, M., Wapner, W. and Gardner, H. Sensitivity to emotional expressions and situations in organic patients. Cortex 16, $145158,1980$.

39. DOnChIN, E., RitTeR, W. and MCCALlum, C. Cognitive psychophysiology: the endogenous components of the ERP. In Eient-Related Brain Potentials in Man, E. Callaway, P. TueTiNg and S. H. Koslow (Editors), pp. 349-411. Academic Press, New York, 1978.

40. WALTER, W. G. The convergence and interaction of visual, auditory, and tactile responses in human nonspecific cortex. Ann. N.Y. Acad. Sci, 112, 320-361, 1964.

41. Swith, D. B. D. Some interrelations between the contingent negative variations and the evoked potentials. Psychophysiology 13, 399-403, 1976. 
Resume :

On a enregistré les potentieis évoques cerebraux chez des adultes tandis qu'ils lisaient 160 phrases differentes dont la moitié finissait par un mot semlantiquement anomal. Ces mots déviants déterminaient une composante négative étendue ( $N$ 400). Mesuré dans l'onde de difference entre les potentiels évoqués selon les terminaisons, congruente ou incongruente. N 400 etait légèrement plus grand et plus prolange sur l'hëmisphère droit que sur l'hémisphère gauche et diminuait d'amplitude au cours de l'expérience. On observait a nouveau une asymetrie plus grande a gauche qu'a droite dans les potentiels évoqués positifs lents produits par les six premiers mots des phrases, asymétrie plus prononcée chez les sujets n'ayant pas de gauchers dans leur famille immédiate.

\section{Zusammeniassung}

Ereignis-korrelierte Hirnpotentiale wurden bei Erwachsenen regist iert, als sie 160 unterschicdliche Säze lasen, von denen die Hălite mit einem semantisch inakzeptablen Wurt endete. Diese abweichenden iyorter lösten eine breite ntigative Komponente (N400) aus. Verglich man den Unterschied der Potentiale bei passenden und unpassenden Satzendigungen, war die N400 etwas breiter und länger über del rechten als über der linken Hemisphäre und verminderte sich in ihrer Amplitude während des Experimentes. Eine Asymmetrie links größer als rechts fand sich wiederum bei den langsimen positiven Reaktionspotentialen, die durch die ersten 6 Wörter in den Sätzen ausgelöst wurden. sie war am deutlichsten bei Versuchspersonen, die keine Linkshander in ihree unmittelbaren Familie hatten. 